\title{
The effects of ethical dilemmas regarding the use of physical restraints in eldercare on female nurses who care for their relatives in Japan
}

\author{
Miwa Yamamoto \\ Department of Nursing, Kyoto Koka Women’s University, Kyoto, Japan \\ Email: tokiwa27@hotmail.com
}

Received 16 September 2011; revised 20 November 2011; accepted 22 February 2012

\begin{abstract}
Purpose: This study sought to clarify the relationship between a nurse's exposure to elderly relatives and their perspective in using restraints on the elderly in health care situations. Methods: We approached nursing staff supervisors at 17 general hospital wards and explained the objectives of the study. Supervisors at 14 hospitals agreed to participate, giving us a sampling pool of 1929 nurses. We used a chi square test to compare nurses who had spent time with elderly relatives and those who had not on several variables related to using restraints on elderly patients. Results and Conclusion: This study found that nurses who live with elderly family members were significantly more likely to believe that restraints cause diseases (including chronic diseases) based on a chi square test $(p<0.05)$. Therefore it would be important that essential was the experiences of individuals with elderly family members when making programs of decreasing nurse's dilemma to restraining the elderly.
\end{abstract}

Keywords: Ethical Dilemmas; Restraints; Female Nurses; Care for Their Relatives

\section{INTRODUCTION}

Researchers report that nurses who use physical restraints on patients experience feelings of frustration, guilt, and ambivalence [1]. Moreover, many studies have verified the harmful effects of physical restraints on patients [2]. Therefore, nurses have mixed emotions when they must use restraints on elderly people [3,4]. Nurses did not face this uncomfortable situation when they were working in the wards. Nurses are influenced by experiences in spending time with the elderly. There is not much published work on this subject in Japan.

\section{PURPOSE}

Previous studies had nurses felt dilemma about using restraints [4], nurses were influenced by experiences in spending time with the elderly [5]. Accordingly, they faced uncomfortable situation in the practice and were influenced with value of individual's experiences. Moreover, they needed a program to prevent dilemma regarding using physical restraints to the elderly, thus, this study sought to clarify the relationship between a nurse's exposure to elderly relatives and their perspective in using restraints on the elderly in health care situations.

\section{METHODS}

We developed an original 8-item survey based on Crisham's research [6,7] and using Kojima's [8] nursing dilemma items as a reference. We approached nursing staff supervisors at 17 general hospital wards (excluding emergency departments, intensive care units and wards of psychiatry, pediatrics, obstetrics, outpatients and surgery) and explained the objectives of the study. Supervisors at 14 hospitals agreed to participate, giving us a sampling pool of 1929 nurses. We used a chi square test to compare nurses who had spent time with elderly relatives and those who had not on several variables related to using restraints on elderly patients.

\section{RESULTS AND CONCLUSION}

We distributed 1929 questionnaires and 1771 were returned representing a $91.8 \%$ response rate. Of the total number, 1463 were female. Dilemma7-item wasn't significant, however, it was significant item "Physical restraint causes diseases, including chronic diseases, and a desire to find an alternative method exists" with experience of spending time with elderly people as family ( $\mathrm{p}<$ 0.05: Table 1).

This study found that nurses who live with elderly family members were significantly more likely to believe that restraints cause diseases (including chronic diseases) based on a chi square test $(\mathrm{p}<0.05)$. Research shows that a nurse is more sensitive about their moral obligetions based on their experiences living with elderly 
Table 1. Experiences of families spending time with elderly patients as related to 8 dilemma items.

\begin{tabular}{|c|c|c|c|c|c|c|c|c|c|}
\hline & \multirow{2}{*}{ Dilemma items } & \multicolumn{7}{|c|}{ Families' experiences in spending time with elderly patients (\%) } & \multirow{2}{*}{ p-value } \\
\hline & & \multicolumn{3}{|c|}{ Yes } & \multicolumn{2}{|c|}{ No } & \multicolumn{2}{|c|}{ Sum } & \\
\hline \multirow{2}{*}{1} & Physical restraint may be allowed for medical & Yes & 261 & $(36.0)$ & 463 & $(64.0)$ & 724 & $(100.0)$ & \multirow{2}{*}{0.31} \\
\hline & refusal. $(n=1105)$ & No & 131 & (34.4) & 250 & $(65.6)$ & 381 & $(100.0)$ & \\
\hline \multirow{2}{*}{2} & Physical restraint at the request of family & Yes & 421 & $(35.7)$ & 759 & (64.3) & 1180 & $(100.0)$ & \multirow{2}{*}{0.19} \\
\hline & patient refuses. $(\mathrm{n}=1263)$ & No & 34 & $(41.0)$ & 49 & $(59.0)$ & 83 & $(100.0)$ & \\
\hline \multirow{2}{*}{3} & Physical restraint is difficult when the patient & Yes & 469 & $(36.6)$ & 812 & $(63.4)$ & 1281 & $(100.0)$ & \multirow{2}{*}{0.52} \\
\hline & $(\mathrm{n}=1346)$ & No & 24 & (36.9) & 41 & $(63.1)$ & 65 & $(100.0)$ & \\
\hline \multirow{2}{*}{4} & Physical restraint of patients having violent & Yes & 403 & (35.9) & 721 & $(64.1)$ & 1124 & $(100.0)$ & \multirow{2}{*}{0.13} \\
\hline & other patients and nursing staff. $(\mathrm{n}=1288)$ & No & 51 & $(31.1)$ & 113 & (68.9) & 164 & $(100.0)$ & \\
\hline \multirow{2}{*}{5} & Physical restraint aggravates dementia & Yes & 520 & $(36.6)$ & 899 & $(63.4)$ & 1419 & $(100.0)$ & \multirow{2}{*}{0.56} \\
\hline & alternative methods are needed. $(n=1449)$ & No & 11 & (36.7) & 19 & (63.3) & 30 & $(100.0)$ & \\
\hline \multirow{2}{*}{6} & Physical restraint reduces the QOL of elderly & Yes & 468 & $(36.1)$ & 829 & (63.9) & 1297 & $(100.0)$ & \multirow{2}{*}{0.30} \\
\hline & are needed. $(n=1426)$ & No & 43 & (33.3) & 86 & $(66.7)$ & 129 & $(100.0)$ & \\
\hline \multirow{2}{*}{7} & Physical restraint causes disease, and & Yes & 433 & $(37.5)$ & 721 & $(62.5)$ & 1154 & $(100.0)$ & \multirow{2}{*}{0.02} \\
\hline & $(\mathrm{n}=1260)$ & No & 29 & (27.4) & 77 & $(72.6)$ & 106 & (100.0) & \\
\hline \multirow{2}{*}{8} & Physical restraint accelerates the decline in & Yes & 518 & $(36.6)$ & 898 & $(63.4)$ & 1416 & $(100.0)$ & \multirow{2}{*}{0.40} \\
\hline & alternative methods are needed. $(\mathrm{n}=1441)$ & No & 8 & (32.0) & 17 & (68.0) & 25 & (100.0) & \\
\hline
\end{tabular}

Data are number of subjects (\%) using a Chi-square test.

family members. This study found that nurses who live with the elderly were significantly more likely to believe that restraints cause diseases (including chronic diseases) based on a chi square test $(\mathrm{p}<0.05)$. Stilwell reported that nurses who use physical restraints on patients experience feelings of frustration, guilt, and ambivalence [1]. Evans \& Strumpf studied also verified the harmful effects of physical restraints on patients [2]. Findings showed that a nurse feels more of a moral obligation when having lived with and cared for an elderly family member. Therefore it is essential to consider the experiences of individuals who provide eldercare to a family member when developing programs to prevent nursing dilemmas with restraining the elderly. Therefore it would be important that essential was the experiences of individuals with elderly family members when making programs of decreasing nurse's dilemma to restraining the elderly.

\section{ACKNOWLEDGEMENTS}

The author thanks all participants of this study.

\section{REFERENCES}

[1] Stilwell, E. (1975) Editorial: Nursing or nursing home
administration-A nurse's dilemma. Journal of Gerontological Nursing, 1, 3-4.

[2] Evans, L. and Frick, M.C. (1989) Potential fatality reductions through eliminating occupant ejection from cars. Accident Analysis \& Prevention, 21, 169-182. doi:10.1016/0001-4575(89)90084-5

[3] Scherer, Y.K., et al. (1991) The nursing dilemma of restraints. Journal of Gerontological Nursing, 17, 14-17.

[4] Yamamoto, M., Izumi, K. and Usui, K. (2006) Dilemmas facing Japanese nurses regarding the physical restraint of elderly patients. Japan Journal of Nursing Science, 3, 4350. doi:10.1111/j.1742-7924.2006.00056.x

[5] Matthiesen, V., et al. (1996) Hospital nurses' views about physical restraint use with older patients. Journal of Gerontological Nursing, 22, 8-16.

[6] Crisham, P. (1981) Measuring moral judgment in nursing dilemmas. Nursing Research, 30, 104-110. doi:10.1097/00006199-198103000-00012

[7] Crisham, P. (1985) Moral: How can I do what's right? Nursing Management, 16, 42A-42N.

[8] Kojima, M. (1997) Mapping for management of dilemmas of nurses-Communication with doctors for nursing focused on patients. Igaku Syoin, Tokyo. 